\title{
Interactive comment on "Investigation of the wet removal rate of black carbon in East Asia: validation of a below- and in-cloud wet removal scheme in FLEXPART v10.4" by Yongjoo Choi et al.
}

Anonymous Referee \#2

Received and published: 20 July 2020

\section{General comments:}

The paper addresses a topic of scientific relevance which is within the scope of Atmospheric Chemistry and Physics. They present a method to evaluate the wet removal rate of black carbon (BC) with the LPDM Flexpart based on long-term measurements over East Asia. The authors used back-trajectories with Hysplit to identify the source region of the air masses from 3 stations over East Asia and to determine the accumulated precipitation along the trajectories. With this information, they calculated the Transport Efficiency (TE) of black carbon from the measurements and compared the TE 
from measurements with the results of the backward modelling with Flexpart v10.4 to assess the simulated wet removal rate in transport modelling. Additionally, the authors further distinguish their evaluation between below cloud and in-cloud wet removal by diagnosing the scavenging coefficients. They show that the wet removal of $\mathrm{BC}$ from the different measurement sites have significant differences and discuss various reasons. According to the scavenging from below and in-cloud, they found that Flexpart underestimates the in-cloud scavenging and overestimates the below-cloud scavenging. By using a neural network, the authors investigated the importance of several dependencies. They found that CAPE is the parameter with the most substantial influence on in-cloud scavenging and suggest to include this parameter in the future.

However, even though the methods and discussions provide valuable assets to the community, they are not easy to understand and clear in the way it was written. I had to re-read multiple sections to identify what was done and which values from which data sets were compared or used. In my opinion, this could be improved by some additional definitions and distinctions. For example, the authors should clearly distinguish between measured data, determined/calculated data and simulated data. For example, I often got confused by the mentioning of Flexpart scheme, since this was sometimes the simulated data and sometimes the algorithm for deposition calculation.

I suggest major revisions as outlined in the comments below and addressing the specific comments before publishing the manuscript.

Major comments:

1. How did you select the simulation setup? Why only $72 \mathrm{~h}$ of backward runs and why starting with a height of $500 \mathrm{~m}$ for the release location? There must have be some investigation or thought on this. What effect does it have on the results?

Printer-friendly version

2. Why do you use two different models with a different data set each? This causes a lot of differences and uncertainties in the results. You mention that you did not find large differences in the pathways between Hysplit with ERA5 and Flexpart with ERA- 
Interim. But there are still differences due to the different physical parameterizations and spatial and temporal resolutions. Wouldn't it be more accurate to use Flexpart for the trajectory calculations also and therefore use the same data set? I know that ERA5 model level data were not easily available for all users in the past, but it is now. Therefore, it would be a substantial improvement to use the same data set, namely ERA5, for all simulations. I am aware that this is probably not possible to achieve within this review process, but the authors should discuss this and provide more details about possible uncertainties.

3. It is not recommended to use all four analysis times $(0,6,12$ and 18 UTC) per day and combine them with forecast fields to achieve 3-hourly temporal resolution. This causes unnecessary inconsistencies between $5 \mathrm{~h}$ and $7 \mathrm{~h}$ as well as $17 \mathrm{~h}$ and $19 \mathrm{~h}$. The recommendation is to use 0 and 12 UTC and fill the times in between with forecast fields. I also thought that ERA-Interim on model levels were only available at $0,6,12$ and 18UTC for public users, which gives me the indication that the access method was as a member-state user? Is this correct? Then you should have had access to ERA5 data all the time anyway.

4. After going through the manuscript I had a hard time to distinguish which data set and scheme/formula was used to calculate TE or scavenging coefficients. I would highly suggest to go through section 3.4 and 3.5 (below and in-cloud scavenging) again and try to be more clear in the description and distinguishing of where a scavenging coefficient comes from. Maybe by giving it different subscriptions.

Specific comments:

1. p.1 I.29: You mention diagnosing the scavenging coefficients from Flexpart. I thought that Flexpart defines the coefficients upfront in a species file. Therefore, I don't understand why the coefficients need to be diagnosed. Could you explain please?

2. p.2 I. 58: ... because TE has been proven .... ; could you provide evidence?

Printer-friendly version

Discussion paper
Interactive

comment 
3. p.2 I. 65: what is meant by "mixing stats" ?

4. p2. I.68-71: This sentence is hard to understand, especially the part with "...polluted areas scavenging in cloud were more...."

5. p.2 I.73: ... could be a useful parameter ... ; I thought it is a useful parameter, why could?

Interactive

comment

6. p.2 I.74: You mention that you adopt APT. You adopt it from where and how?

7. p.3 I.82: What are the administrative districts? Could you provide a plot?

8. p3. I.85: Again, you estimate the scavenging coefficients from FLEXPART? Why? I sense that I might miss or misunderstand something.

9. p.3 1.93: What does "intensive" in this context mean? Do you really mean intensive?

10. p.3 I.98: "The measurement periods were mainly in the early 2010 s ... "; Do you mean that they start in the early 2010s ?

11. p.3 1.99: Since Figure $S 1$ is in the supplement, you might want to add a note on that.

12. p.3 I.101: "well-validated"; What is well-validated? There should be a criterion for this.

13. p.4 I.118: Why mentioning GDAS?

14. p.4 I.119: Do the pressure levels correspond to ERA5 or GDAS?

15. p.4 I.121: Did you disaggregate the precipitation fields as they are done for Flexpart simulations? For better comparison to Flexpart results.

16. p. 4 I.124: What are the main $\mathrm{BC}$ regions? How is "main $\mathrm{BC}$ region" defined?

Printer-friendly version

17. p.4 I.125: Why couldn't the precipitation not be overestimated?

Discussion paper

18. p.5 I.150: What do the global models have to do with this study? 
19. p5. I.155: shouldn't there be a reference to the Flexpart v10.4 paper?

20. p.5 I.159: ERA-Interim is not an operational reanalysis. ERA-Interim was suspended and ERA5 is now operational!

21. p.5 I.159-160: You should rewrite to "60 model levels" since vertical levels could also be pressure levels or others.

Interactive

comment

22. p. 5 I.160: "ECMWF has a resolution of $3 \mathrm{~h} . .$. " this is wrong. The ERA-Interim data set has this resolution, but not ECMWF in general.

23. p.5 I.168: what do you mean by "extracted" ? How do you calculate the TE with Flexpart data.

24. p.5 I.174: Could you define the bins somewhere? This should be done according to be able to reproduce the results.

25. p.5 I.178: What was $R^{2}$ before it was improved?

26. p.5 I.183: This Fukue site comes out of nowhere and it is not clear where it is located.

27. p.6 I.187: I don't understand how the new SED indicates the transport to the Artic, please explain further.

28. p.6 I.214: what global model?

29. p.7 I.224: “ A similar tendency of $\mathrm{R}^{2}$, $\mathrm{TE}=0.5$ also showed .. " ; I don't understand this formulation. Do you mean $R^{2}$ and TE ?

30. p.8 I.258: wasn't this described in Grythe et al. 2017 ?

31. p.8I.258-261: Its not only the grid resolution but the whole model physics is different apart from the differences between Hysplit and Flexpart. Additionally, regional/local pattern of precipitation and clouds are totally different especially because Flexpart uses disaggregated precipitation while it seems that Hysplit and ERA5 data used in this 
study weren't disaggregated. How does this reflect in the results? And why did you chose $1^{\circ} \times 1^{\circ}$ for ERA-Interim instead of the $0.75^{\circ} \times 0.75^{\circ}$ resolution ERA-Interim was stored on?

32. p.8I. 274.: In this section, I got confused by the values from measured vs ERA5 vs calculated vs reported vs Flexpart. Did you calculate the TE with the Flexpart scheme from ERA5 data? Then, what did you use from Flexpart simulation results?

33. p.8 I.301: again, could you please define the bins somewhere? (reproducabilty)

34. p.8 I.307: what are reported values?

35. p.8 I.319: could you give a reference for your statement of " the effect of differences in diameter might be negligible" please?

36. p.10 I.333: the Flexpart scavenging coefficient is taken from the simulations with ERA-Interim data and the estimated coefficient is from the measurement data in combination with the scheme from Flexpart and ERA5 data? Is this correct?

37. p10. I.362: what would be the effect if it would be $4: 1$ or $2: 1$ ?

38. Table 2: Does this mean Flexpart does not correspond to the ERA-Interim simulation results but to the calculated values with ERA5 data and the Flexpart scheme? If not, reformulate please.

Technical corrections:

p.3 I.83: Afterward $\rightarrow$ Afterwards p.5 I.150: remove "but" p.5 I.150: negligible $\rightarrow$ neglected p.5 I.153: I would suggest to exchange the order of "model simulation" and "measured values" p.5 I.166: were existed $\rightarrow$ were available p.7 I.223: was varied $\rightarrow$ varied p.7 I.230: "than the dominat in-cloud ..." $\rightarrow$ than in the dominant ... p.7 I.249: simulation $\rightarrow$ simulations

Interactive comment on Atmos. Chem. Phys. Discuss., https://doi.org/10.5194/acp-2020-402, 2020. 